\title{
Lumbar Disc Herniations 'To Operate or Not' Patient Selection and Timing of Surgery
}

\author{
Gazanfar Rahmathulla ${ }^{1}$, Kambiz Kamian ${ }^{2}$ \\ ${ }^{l}$ Department of Neurosurgery, Mayo Clinic, Jacksonville, Florida, \\ ${ }^{2}$ Department of Neurosurgery, Cleveland Clinic, Cleveland, Ohio, USA
}

At times lumbar disc herniations present a quandary to the spine surgeon in regards to the most appropriate intervention and a need to optimize medical and surgical therapies. We discuss a case of ours and our experience in treating this common spinal pathology, along with a commentary on the article published by Kim et al. entitled 'Spontaneous regression of extruded lumbar disc herniation: three cases report in Korean J Spine. 2013 Jun;10(2):78-81.'

Key Words: Lumbar disc $\cdot$ Disc herniation $\cdot$ Management $\cdot$ Surgery $\cdot$ Medical

We would like to elaborate on some of the issues brought up by Kim et al. ${ }^{15)}$ in their article in Korean Journal of Spine regarding spontaneous disk regression in a recent publication entitled 'Spontaneous regression of extruded lumbar disc herniation: three cases report.' 2013 Jun;10(2):78-81.

Lumbar disc herniations remain one of the most common reasons for a visit to the spine surgeon, being a significant contributor to low back pain and lower extremity radicular syndrome. The therapeutic approach ranges from conservative medical interventional management to surgery. Although there is a significant body of literature on the various management options and outcomes, as predicted, there is no uniform consensus regarding the most appropriate interventions and specifically the timing of surgical intervention. At symptom onset, in the absence of any neurological deficits, conservative medical treatments are initially attempted and have known therapeutic efficacy. Various studies have also confirmed the effectiveness of surgery in the initial management of lumbar disc herniations. In the absence of symptoms resolution, surgical intervention is usually performed anywhere between two and twelve months following the onset of pain. In our experience the presence of neurological deficits at with the onset of radicular such as muscle weakness, cauda equina syndrome or a progressive deficit while being medically managed, make early

- Received: June 1, 2014 • Revised: June 22, 2014

- Accepted: June 25, 2014

Corresponding Author: Gazanfar Rahmathulla, MD

Department of Neurosurgery, Mayo Clinic, 4500 San Pablo Rd,

Cannaday $2 \mathrm{E}$, Jacksonville, Florida 32224, USA

Tel: + 1-904-953-2000, Fax: + 1-888-9394093

E-mail: drgazanfar@gmail.com

@This is an Open Access article distributed under the terms of the Creative

Commons Attribution Non-Commercial License (http://creativecommons.org/ licenses/by-nc/3.0/) which permits unrestricted non-commercial use, distribution, and reproduction in any medium, provided the original work is properly cited. surgical intervention essential and give the patient the best opportunity for neurological recovery ${ }^{22}$.

We recently had 52 year old gentleman presented with a lumbar disc herniation and radicular pain without any focal neurological deficits. Magnetic resonance imaging (MRI) of his lumbar spine revealed an $\mathrm{L} 2 / 3$ disc herniation with a large extruded fragment (Fig. 1A, B \& C). His associated co-morbidities included smoking, diabetes and obesity. We opted to manage this patient conservatively with pain medications, initial rest for no longer than 48-72 hours followed by a gradual physical therapy rehabilitation program. We decided to on a subsequent clinical follow-up at 12 weeks and then 6 months depending on the nature of his symptoms
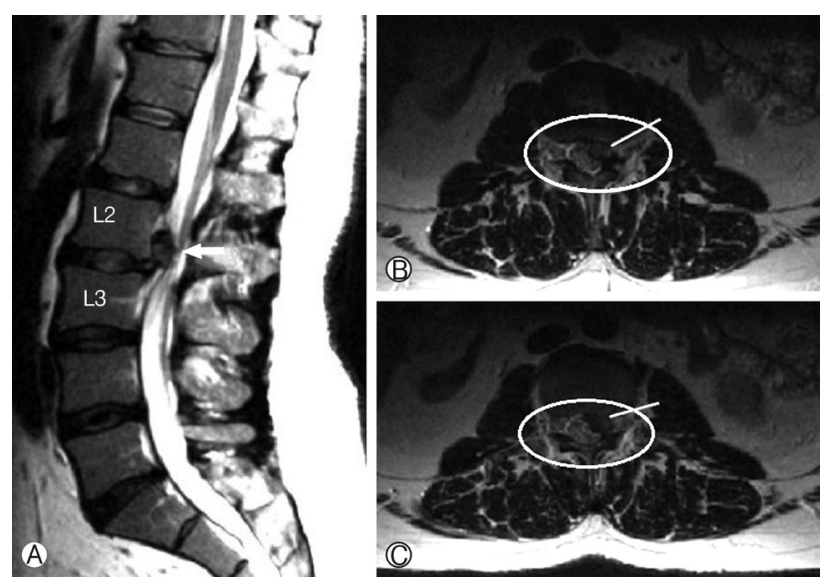

Fig. I. (A) Sagittal T2 WI-MRI reveals an L2-3 herniated disk fragment migrating upwards. (B) Axial T2 WI reveals a left sided paracentral extruded disk fragment. (C) Axial T2 Wl at the level of the $L 2 / 3$ disk space revealing the extruded fragment almost encroaching the foramen. 


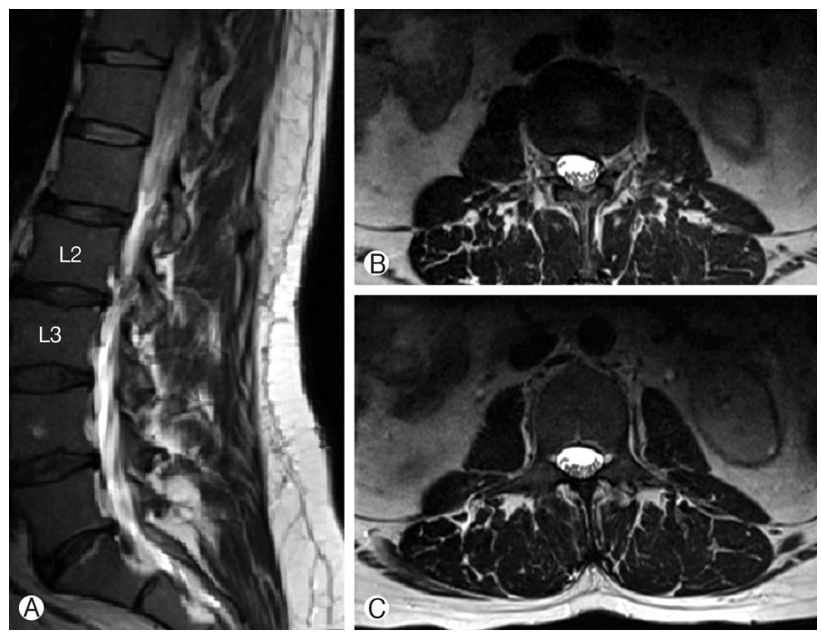

Fig. 2. (A) Follow-up T2 W MRI sagittal images revealing resolution I regression at the $L 2 / 3$ disk level ( $B$ \& C) Axial T2 Wl revealing absence of any disk fragment across the $L 2 / 3$ disk levels.

and ability to continue his daily activities. His radicular pain had gradually subsided at 9 months at which time we repeated the MRI of his lumbar spine. The MRI revealed a resolution in the extruded fragment without any neural compression and the absence of pain (Fig. 2A, B \& C).

Kim et al. have published a report of 3 cases that were managed conservatively in their practice with good symptomatic and radiological resolution ${ }^{15}$. We concur with the authors in the rarity of this finding in practice, although we often do not image patients who have had resolution of their radicular symptoms. In our practice, a majority of our patients who have an extruded or trans-ligamentous herniated fragments that remains within the confines of the spinal canal, with minimal foraminal, trans-foraminal or far lateral extension are ideal candidates to get an initial trial of conservative medical interventional therapies. As will be noted in the MRI imaging seen in the 3 cases reported by Kim et al. as well as our case, the patients that have shown regression have fragments within the spinal canal. In a more recent report by Kim E et al. ${ }^{14)}$, in the 3 cases they reported, one patient developed spontaneous resolution as early as 2 months, whereas another did not have any evident disc identified during surgery. A review of their cases reveals similar MRI findings in their cases. There have been other reports in literature describing spontaneous regression of lumbar discs with various theories for this infrequently seen phenomenon ${ }^{1,2,10,13,19)}$.

The dilemma in patient selection occurs when a patient presents with sciatica in the absence of a neurological deficits that is associated with a large herniated lumbar disc fragment. If surgery is the treatment path, what is the ideal time to intervene in order to give the patient the best outcome? Has early surgery proven to give better results or is it better to delay surgery? When we review literature regarding the natural history of lumbar disk herniation with and without surgery, initial surgery appears to provide good symptomatic relief, however outcomes at 2 years following surgical treatment vs. no surgery (medical interventional modalities) interventional modalities remain the same $e^{3-5,7,8,11,16}$. When we review the time to surgical intervention, literature is replete with a number of studies addressing the issue of surgical timing ${ }^{6,9,12,17,18,21)}$. Although there is a wide range of between 2 and 12 months as being best for surgical intervention, we tend to intervene earlier in far lateral and foraminal disc herniations. For central and paracentral disk herniations we recommend waiting as long as 9 months with medical interventional management. However if the patients pain is unbearable and significantly affects their activities of daily living, quality of life and ability to return to work, earlier intervention at around 5-6 months would be of benefit. This may also prevent the development of a chronic pain syndrome which could lead to a cycle unresponsiveness to later surgical intervention. Earlier intervention at 6-8 weeks may be an option in cases of worsening pain with the onset of a new neurological deficit. In our patient it took 9 months for the disk and pain to resolve, however the patient's pain profile during follow-up had a diminishing trend with more control of his pain. If at 6 months the same patient was symptomatically worse we would have offered surgery. In addition to timing of surgery there are a number of other variables like age, weight, body mass index, smoking, physical activity levels that need to be taken into account, and affect the outcomes of disk surgery ${ }^{20)}$.

Our recommendations are for surgical intervention lie anywhere between 6 months to a year taking into accounts all the patient variables and image findings. Although some surgeons would prefer earlier intervention at 6 weeks, we feel that in the absence of neurological deficits 6 months gives the patient time to try out various medical/interventional therapies. Beyond a year, we generally repeat MRIs of the lumbar spine as degenerative disk disease is a dynamic process and changes over this time can alter our surgical strategy. Acute or emergent surgeries in our practice are recommended in the patient with neurological deficits along with pain at initial presentation or during the course of medical interventional management. The ongoing debate indicates that there is more work ahead and larger randomized trials with similar patient profiles may help answer this simple yet baffling question.

\section{REFERENCES}

1. Ahn SH, Ahn MW, Byun WM: Effect of the transligamentous 
extension of lumbar disc herniations on their regression and the clinical outcome of sciatica. Spine 25:475-480, 2000

2. Autio RA, Karppinen J, Niinimaki J, Ojala R, Kurunlahti M, Haapea M, et al: Determinants of spontaneous resorption of intervertebral disc herniations. Spine 31:1247-1252, 2006

3. Awad JN, Moskovich R: Lumbar disc herniations: surgical versus nonsurgical treatment. Clinical Orthopaedics and Related Research 443:183-197, 2006

4. Baldwin NG: Lumbar disc disease: the natural history. Neurosurgical Focus 13:E2, 2002

5. Benson RT, Tavares SP, Robertson SC, Sharp R, Marshall RW: Conservatively treated massive prolapsed discs: a 7-year followup. Annals of the Royal College of Surgeons of England 92:147153, 2010

6. Blazhevski B, Filipche V, Cvetanovski V, Simonovska N: Predictive value of the duration of sciatica for lumbar discectomy. Prilozi/Makedonska akademija na naukite i umetnostite, Oddelenie za bioloski i medicinski nauki=Contributions/Macedonian Academy of Sciences and Arts, Section of Biological and Medical Sciences 29:325-335, 2008

7. Bush K, Cowan N, Katz DE, Gishen P: The natural history of sciatica associated with disc pathology. A prospective study with clinical and independent radiologic follow-up. Spine 17: 1205-1212, 1992

8. Delgado-Lo Pez PD, Rodri Guez-Salazar A, Castilla-Di Ez JM, Marti NVV, Ferna Ndez-Arconada O: [Role of surgery in spinal degenerative disease. Analysis of systematic reviews on surgical and conservative treatments from an evidence-based approach]. Neurocirugia 16:142-157, 2005

9. Folman Y, Shabat S, Catz A, Gepstein R: Late results of surgery for herniated lumbar disk as related to duration of preoperative symptoms and type of herniation. Surgical Neurology 70:398401; discussion 401-392, 2008

10. Gelabert-Gonzalez M, Serramito-Garcia R, Aran-Echabe E, Garcia-Allut A: [Spontaneous resolution of a lumbar disc herniation]. Neurocirugia 18:138-140, 2007

11. Gibson JN, Waddell G: Surgical interventions for lumbar disc prolapse: updated Cochrane Review. Spine 32:1735-1747, 2007

12. Junge A, Frohlich M, Ahrens S, Hasenbring M, Sandler A, Grob
D, et al: Predictors of bad and good outcome of lumbar spine surgery. A prospective clinical study with 2 years' follow up. Spine 21:1056-1064; discussion 1064-1055, 1996

13. Kato T, Haro H, Komori H, Shinomiya K: Sequential dynamics of inflammatory cytokine, angiogenesis inducing factor and matrix degrading enzymes during spontaneous resorption of the herniated disc. Journal of orthopaedic research: official publication of the Orthopaedic Research Society 22:895-900, 2004

14. Kim ES, Oladunjoye AO, Li JA, Kim KD: Spontaneous regression of herniated lumbar discs. Journal of clinical neuroscience: official journal of the Neurosurgical Society of Australasia 21: 909-913, 2014

15. Kim SG, Yang JC, Kim TW, Park KH: Spontaneous regression of extruded lumbar disc herniation: three cases report. Korean Journal of Spine 10:78-81, 2013

16. Komori H, Shinomiya K, Nakai O, Yamaura I, Takeda S, Furuya $\mathrm{K}$ : The natural history of herniated nucleus pulposus with radiculopathy. Spine 21:225-229, 1996

17. Mannion AF, Junge A, Elfering A, Dvorak J, Porchet F, Grob D: Great expectations: really the novel predictor of outcome after spinal surgery? Spine 34:1590-1599, 2009

18. Ng LC, Sell P: Predictive value of the duration of sciatica for lumbar discectomy. A prospective cohort study. The Journal of bone and joint surgery. British Volume 86:546-549, 2004

19. Reyentovich A, Abdu WA: Multiple independent, sequential, and spontaneously resolving lumbar intervertebral disc herniations: a case report. Spine 27:549-553, 2002

20. Sabnis AB, Diwan AD: The timing of surgery in lumbar disc prolapse: A systematic review. Indian Journal of Orthopaedics 48:127-135, 2014

21. Silverplats K, Lind B, Zoega B, Halldin K, Rutberg L, Gellerstedt $\mathrm{M}$, et al: Clinical factors of importance for outcome after lumbar disc herniation surgery: long-term follow-up. European spine journal: official publication of the European Spine Society, the European Spinal Deformity Society, and the European Section of the Cervical Spine Research Society 19:1459-1467, 2010

22. Sonntag VK: Why not decompress early? The cauda equina syndrome. World Neurosurgery, 2014 